\section{The Determination of Mobility and Immobility of Water Adsorbed in Type 5A and 13X Zeolites by IR and DTA}

\section{F. Ucun}

Physics Department, Faculty of Arts and Sciences, Süleyman Demirel University, Isparta, Turkey

Reprint requests to Dr. F. U.; Fax: +90-246-237 1106 ;

E-mail:fucun@fef.sdu.edu.tr

Z. Naturforsch. 57a, 281-282 (2002);

received August 6, 2001

In this study, infrared (IR) and differential thermal analysis (DTA) data were used to investigate the mobility of water adsorbed in synthetic zeolites of type $5 \mathrm{~A}$ and $13 \mathrm{X}$ with pore diameters of 5 and $10 \AA$, respectively. The results indicate that there are at least two types of water, mobile and immobile ones, in the narrow pore zeolite, while there is only mobile water in the wide pore zeolite.

Key words: IR; DTA; Mobility of Water; Type 5A Zeolite; 13X Zeolite.

The dynamics of water molecules adsorbed in porous systems can be studied by using metal ion complexes as paramagnetic probes [1-3]. Such studies give information about the localization and structure of adsorbed complexes and about the behavior of the adsorbed water.

In our previous study, by electron spin resonance (ESR) the mobility and freezing properties of water adsorbed in synthetic zeolites of type 3A, 4A, 5A, and $13 \mathrm{X}$ with pore diameters of $3,4,5$, and $10 \AA$, respectively, and the natural zeolites heulandite and clinoptilolite were studied using the $\mathrm{Cu}\left(\mathrm{H}_{2} \mathrm{O}\right)_{6}^{2+}$ complex as paramagnetic probe [4]. It was found that in the narrow-pore zeolites type 3A, 4A, and 5A the first layers of water molecules on the surfaces are restricted in motion even at room temperature, whereas beyond these the water molecules are mobile, the water molecules in wide pore and natural zeolites behaving like liquid water. These results are good agreement with our other study, where $\operatorname{VO}\left(\mathrm{H}_{2} \mathrm{O}\right)_{5}^{2+}$ and $\mathrm{Mn}\left(\mathrm{H}_{2} \mathrm{O}\right)_{6}^{2+}$ complexes were adsorbed on the same zeolites [5].

In the present study these results were confirmed by analysis of IR and DTA spectra of water adsorbed in type $5 \mathrm{~A}$ and $13 \mathrm{X}$ zeolites.

\section{Experimental Details}

The synthetic zeolites of the type 5A and $13 \mathrm{X}$ were purchased from the British Drug House (BDH). The unit cells of these zeolites were given in [1]. Firstly the zeolites were activated at $473 \mathrm{~K}$ for $4 \mathrm{~h}$. Then, aqueous solutions of $\mathrm{CuCl}_{2}$ of $5 \cdot 10^{-3} \mathrm{M}$ were prepared in distilled water. $1 \mathrm{~g}$ of the zeolites was put into $20 \mathrm{~cm}^{3}$ of this solution, stirred and stored at room temperature for $24 \mathrm{~h}$. Then, the solutions were filtered and the zeolites were dried at room temperature.

The IR spectra were recorded on disks of powdered material with a Perkin Elmer Model 1430 Infrared Spectrophotometer. The DTA and thermogravimetry (TG) curves were obtained from the Thermal Analysis Station Rigaku TAS 100.

\section{Results and Discussion}

The IR spectra of the zeolites of type 5A and $13 \mathrm{X}$ adsorbed $\mathrm{CuCl}_{2}+$ water with taken at room temperature, are shown in Fig. 1 with the spectra of their pure states. The IR spectrum of the type 5A zeolite has two peaks, showing that there are two kinds of water. These are mobile and immobile water, which can be seen in Fig. 1a) (1). The peak at $3420 \mathrm{~cm}^{-1}$ belongs to the mobile water and that at $3590 \mathrm{~cm}^{-1}$ belongs to the zeolitic water. The peak at $3520 \mathrm{~cm}^{-1}$ (Fig. 1a) (2)) in the IR spectrum of the type $5 \mathrm{~A}$ zeolite adsorbed $\mathrm{CuCl}_{2}+$ water that appears at higher energy with then the others is attributed to the vibration of zeolitic water. The peaks at 3350 and $3445 \mathrm{~cm}^{-1}$ in Fig. 1a) (2) are attributed to mobile and immobile water in zeolitic pores, respectively. Since the environment of the zeolitic water changes with the inclusion of water adsorbed on the type $5 \mathrm{~A}$ zeolite, the IR peak seen at $3590 \mathrm{~cm}^{-1}$ in Fig. 1a (1) shifts towards $3520 \mathrm{~cm}^{-1}$ in Fig. 1a) (2). It is impossible to state these for the $13 \mathrm{X}$ zeolite because there it gives only a peak in the water region of the IR spectrum was shown in Fig. 1b). This peak contains zeolitic and mobile water.

The DTA plays an important role in the detection of mobile and immobile water. DTA and TG curves of water adsorbed in type $5 \mathrm{~A}$ zeolite have three dehydration steps at 318, 401, and $460 \mathrm{~K}$ (Fig. 2a). Dehydration in three steps is attributed to the difference in bonding strength of the water molecules in the type $5 \mathrm{~A}$ zeolite. These dehydration steps exist also in the DTA curve of pure type 5A zeolite but appear at higher temperatures and lower intensities. Mobile water on surfaces and in pores are removed at 318 and $401 \mathrm{~K}$, respectively. Immobile water in pores is removed at $460 \mathrm{~K}$. 

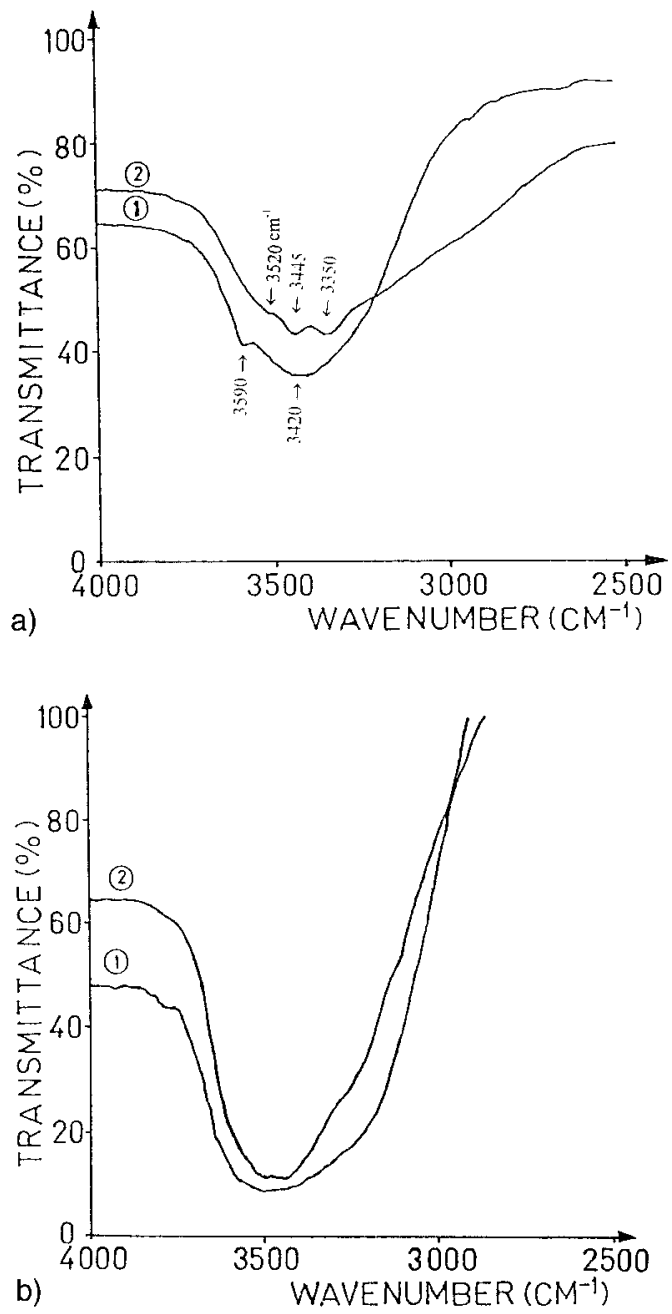

Fig. 1. IR spectra of a) (1) zeolite of type 5A pure, (2) zeolite of type $5 \mathrm{~A}$ with adsorbed $\mathrm{CuCl}_{2}+$ water. b) (1) zeolite of type $13 \mathrm{X}$ pure, (2) zeolite of type $13 \mathrm{X}$ with adsorbed $\mathrm{CuCl}_{2}^{+}$water.

The DTA curve of the $13 \mathrm{X}$ zeolite shows almost only one step of dehydration at $369 \mathrm{~K}$ (Fig. 2b). We attribute this dehydration step to mobile water. Essentially, the very low endothermic peak at $319 \mathrm{~K}$ does not appear in the DTA trace of pure $13 \mathrm{X}$ zeolite. It gives only a wide peak at $420 \mathrm{~K}$ which belongs to mobile water.

[1] L. Burlammacchi, G. Martini, and M. F. Ottaviani, J. Chem. Soc., Faraday Trans II 72, 324 (1976).

[2] G. Martini and L. Burlammacchi, Chem. Phys. Lett. 41, 129 (1976).

[3] L. Burlammacchi and G. Martini, Magnetic Resonance Colloid Interface Sci. 1980; 621.
Note
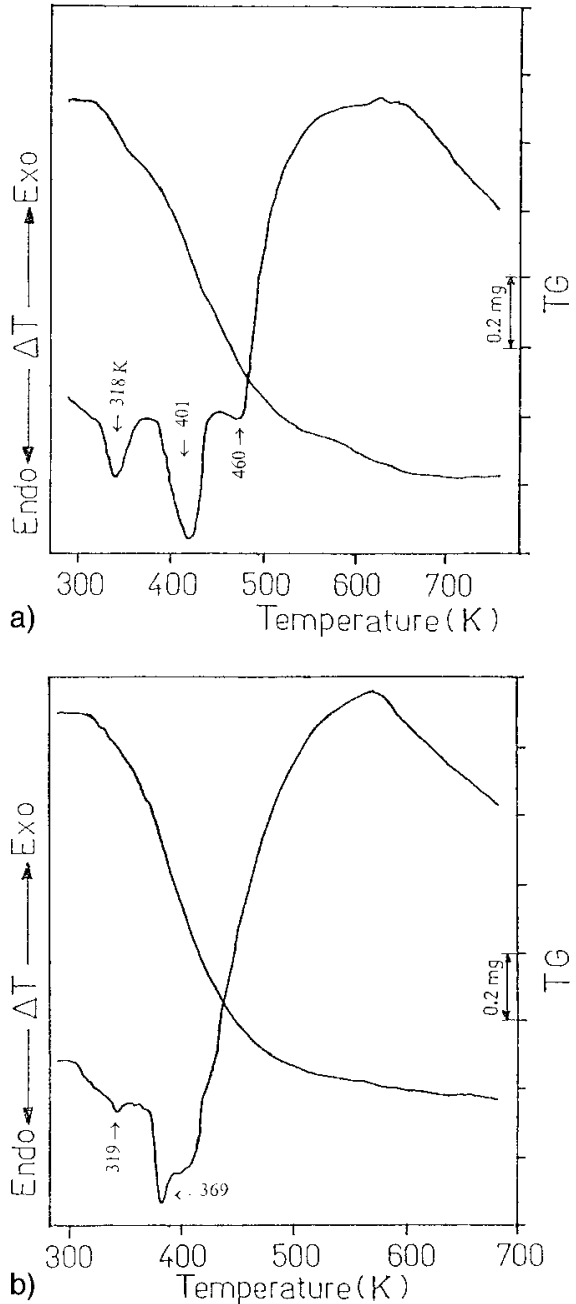

Fig. 2. DTA and TG results for a) zeolite of type $5 \mathrm{~A}$ with adsorbed $\mathrm{CuCl}_{2}+$ water, $5.72 \mathrm{mg}$, and b) zeolite of type $13 \mathrm{X}$ with adsorbed $\mathrm{CuCl}_{2}^{+}$water, $5.42 \mathrm{mg}$.

\section{Conclusion}

From these results it is concluded that at least two types of water are adsorbed in the narrow pore type $5 \mathrm{~A}$ zeolite. These are mobile and immobile water. Only mobile water is adsorbed in the wide pore zeolite $13 \mathrm{X}$.

[4] F. Ucun, F. Koksal, and R. Tapramaz, Zeolites 12, 420 (1992).

[5] F. Ucun and F. Koksal, Z. Naturforsch. 51a, 23 (1995). 